\title{
Late presenting lateral condyle fracture of the humerus in children - clinical outcome of surgical fixation
}

\author{
Reddy P. K. P', Veerabhadra $\mathbf{J}^{2}$
}

${ }^{1}$ Dr. Praveen Kumar Reddy P, Assistant Professor, ${ }^{2}$ Dr. Veerabhadra Javali Assistant Professor; both authors are attached with Department of Orthopedics, Navodaya Medical College and Research Centre, Raichur, Karnataka, India.

Address for Correspondence: Dr. Veerabhadra Javali, Assistant Professor, Department of Orthopedics, Avodaya Medical College Hospital and Research Center, Raichur, Karnataka, India. Permanent address: Dr. Veerabhadra Javali, Room no 39, Fourth floor, RIMS doctors staff quarters, RIMS Medical College, RIMS, Hyderabad Road, Raichur, Karnataka, India. EMail ID: drjavali@yahoo.co.in,drjavali5483@gmail.com (alternate).

\begin{abstract}
Aim: To assess the surgical outcome of Late presenting lateral condyle fracture of the humerus in children with open reduction k-wire/cancellous screw fixation. Material and Methods: After obtaining approval of the ethics committee, a prospective study was conducted in the department of orthopedics Navodaya Medical College and research center, Raichur from March 2015 to August 2016. 13 cases of Late presenting lateral condyle fracture of the humerus in children underwent surgery with k-wire/cancellous screw fixation. We evaluated scoring system proposed by Dhillon et al. to determine the outcomes. Results: There were 9 males and 4 females with a mean age of 7 years and 3 months (range 4-13 years). The average time interval between injury and internal fixation was 4.1 weeks. (Range 3 weeks to 7 weeks). In our study 5 patients got Excellent; 6 patients Good; 2 patients Fair; and 1 patient got Poor results. We encountered major complication in 1 patient who devolved AVN lateral condyle of humerus. Minor complications were noted in total 5 patients. Pin tract infection was the most common in 3 patients and one patient had residual flexion deformity of 15 degree with ROM of 110 degree and another patient had stiffness of elbow. Conclusion: We conclude from our study that late presenting fracture of lateral condyle of humerus needs surgical intervention which can be reasonably reduced and union achieved obtaining satisfactory functional outcome.
\end{abstract}

Key words: Lateral condyle fracture humerus, k-wire fixation, Cancellous screws

\section{Introduction}

Lateral condyle fractures of the humerus are one of the commonest fracture occurring at the age of 5 -10 years, second only to the supracondylar fracture of the humerus in occurrence [1].

The most often used classification (Jacobs classification) of lateral humeral condyle fractures is based on the amount of displacement between the fragments, Type I has $<2 \mathrm{~mm}$ displacement of the metaphyseal fragment, Type II has $2-4 \mathrm{~mm}$ displacement, and Type III, is completely displaced with rotation.

Non displaced fractures can easily be treated with a cast, however open reduction and internal fixation (ORIF) is the treatment of choice for most type 2 and type 3 fractures [2]. Delayed presentation of lateral condylar

Manuscript Received: $7^{\text {th }}$ September 2017

Reviewed: $17^{\text {th }}$ September 2017

Author Corrected: $25^{\text {rd }}$ September 2017

Accepted for Publication: $30^{\text {th }}$ September 2017 fractures of the humerus is relatively common in the developing regions of the world. These fractures are difficult to manage because of the displacement and fibrosis around the condylar fragment secondary to the delay.

The management of these fractures when presented late is controversial $[3,4.5]$. Several studies have found that open reduction at more than 3 weeks after fracture offered no benefit versus no treatment at all $[4,6,7]$.

However, Wattenbarger et al reported good results by open reduction in late presenting children with no avascular necrosis (AVN) of the capitellum [5]. This study was undertaken to assess the functional outcome of cases that presented late and were managed by open reduction and internal fixation with $\mathrm{k}$-wire or cancellous screw. 
Original Research Article

\section{Material and Methods}

Study Design- It is a prospective study of 13 patients carried out from March 2015 to August 2016 admitted to Navodaya Medical College and research center, Raichur, after approval from institutional ethical committee.

Setting- A detailed history was elicited from the patients to reveal the duration of injury and the mode of injury. Radiographs of the distal humerus were obtained in anteroposterior and lateral views. We classified the fractures based on the Jacobs classification of lateral humeral condyle [7]. Patients were recruited according to particular inclusion and exclusion criteria.

\section{Patient Selection}

1. All lateral condyle fractures of the humerus in pediatric patients

2. Only closed fractures were considered

\section{Inclusion criteria}

1. Patients above 4 years and less than 14 years age.

2. Jacobs type II and III fractures

3. Fracture with minimum 3 weeks post injury

\section{Exclusion criteria}

1. Jacob type I fractures

2. Open fractures

3. Lateral condyle fractures with associated ipsilateral injuries

Data Source- All the cases were treated at Navodaya Medical College and research center, Raichur between March 2015 to August 2016 and followed up for a year.

Study size -13 patients of closed lateral condyle fracture of humerus.

After obtaining necessary investigations and surgical fitness, patients were informed for usual surgical risks and obtained informed valid consent. Then patients were subjected to open reduction and k-wire fixation or cancellous screw fixation under Image intensifier control. The timing of the operation was 3 weeks to 7 weeks post- injury with mean period of 4.1 weeks. The surgery was performed under general anaesthesia or brachial block.

Technique: After anesthesia, the patient was positioned in the supine position. All the surgeries were performed under tourniquet control to minimize blood loss. Parts were painted with povidine iodine solution and sterile drapes were applied with adequate exposure of the whole elbow. A lateral approach was made to the elbow. Dissection is through the plane between the triceps and the brachioradialis. The fragment was often found to be displaced and fibrous tissue often made it difficult to assess the orientation of the fracture. Careful dissection of the fibrous tissue was made and displaced fragment was reduced under direct visualization, often with the aid of a reduction clamp or towel clamp and then secured by two 1.5-2 mm Kirschner (K) wires placed either parallel or in a divergent manner starting from metaphysis to taking purchase on the opposite cortex. Screw fixation $(4.0 \mathrm{~mm}$, cancellous) was done in 2 patients where the fragment was big. The K wires were bent approximately $1 \mathrm{~cm}$ protruding outside the skin to facilitate the later on removal of these $\mathrm{K}$ wires.

Post operatively all patients underwent a common protocol of 4-6 weeks long arm slab immobilization. At 6 weeks the Kirschner wire/cancellous screw was removed. The patient was allowed to do range of motion exercises without any protection at 6 weeks. All patients were followed up at 4, 6, 12 weeks, 6 months and one year after surgery. Radiologically union, avascular necrosis, nonunion and heterotropic ossification were looked at.

For functional evaluation, range of elbow motion, presence of tenderness and pain on elbow motion and the signs of ulnar neuropathy were checked and carrying angle was measured. The final functional results were assessed using the scoring system proposed by Dhillon et al.[4] was used. This scoring system includes pain on activity, range of motion, and carrying angle (Table 1). Functional grading (points): Excellent 6, Good 5. Fair 4, Poor $<4$. Overall grading (points): Excellent 9, Good 7-8. Fair 5-6, Poor $<4$. 
Table-1: Scoring system for the outcome of fractures of the lateral humeral Condyle in children proposed by Dhillon et al [4].

\begin{tabular}{|c|c|c|c|}
\hline \multicolumn{2}{|c|}{ Function } & Carrying Angle (Degree) & $\begin{array}{c}\text { Score Points } \\
\text { Each coloumn }\end{array}$ \\
\hline Pain & Range of motion (deg) & Valgus 7 - 10 & 2 \\
\hline None & $0-140$ & Valgus $<20$ & 1 \\
\hline Occasional & $>15-125$ & Varus $<0$ & 0 \\
\hline $\begin{array}{c}\text { After heavy work (or } \\
\text { activities) }\end{array}$ & $>30-110$ & Valgus 20 - 30 & \\
\hline With normal activity & $>30-110$ & Varus 0 - 15 & \\
\hline
\end{tabular}

Functional grading (points): Excellent 6, Good 5. Fair 4, Poor $<4$. Overall grading (points): Excellent 9, Good 7-8. Fair 5-6, Poor $<4$.

\section{Results}

All the patients were available for follow up in our study. The average age was 7 years and 3 months (range 4-13 years). Out of the 13 patients, 9 were male and 4 were females. 8 patients sustained injury to right lateral condyle of humerus compared to 5 who sustained injury to the left.

Out of 13 patients, 8 got injured due to fall on the ground, 2 patients met road traffic accident and 3 patient sustained injury in sport activity. Out of 13 patients 8 cases had taken treatment from traditional bonesetters. Patient demo-graphic and clinical data are presented in Table 2.

Table- 2: Demographic and clinical characteristics of 13 patients who underwent surgery.

\begin{tabular}{|c|c|}
\hline Characteristic & No. \\
\hline Age in years (mean) & 7 years 3 months \\
\hline Male & 9 \\
\hline Female & 8 \\
\hline Right humerus & 5 \\
\hline Left humerus & 8 \\
\hline Fall on ground & 2 \\
\hline RTA & 3 \\
\hline Sports activity & 9 \\
\hline
\end{tabular}

The mean duration of surgery was 42.39 minutes (range: 30-75 min). In 11 patients we did open reduction internal fixation with k-wires. In 2 patients, we did open reduction internal fixation with cancellous screws as the distal fragment was big. We encountered major complication in 1 patient who devolped AVN lateral condyle of humerus and no other complications of nonunion, deep infection was seen.

Minor complications were noted in total 5 patients. Pin tract infection was the most common in 3 patients and one patient had residual flexion deformity of $15 \mathrm{deg}$ with ROM of $110 \mathrm{deg}$ and another patient had stiffness of elbow. There were no neurovascular complications.

At the latest follow up overall outcome according to the scoring system proposed by Dhillon et al.[4] was excellent in 5 patients $(38.46 \%)$, good in 5 patients $(38.46 \%)$, fair in 2 patient $(15.38 . \%)$, and poor in 1 patient $(7.6 \%)$. Radiographic course of two cases of lateral condyle fracture of humerus is depicted in the [Fig. 1 and 2]. 


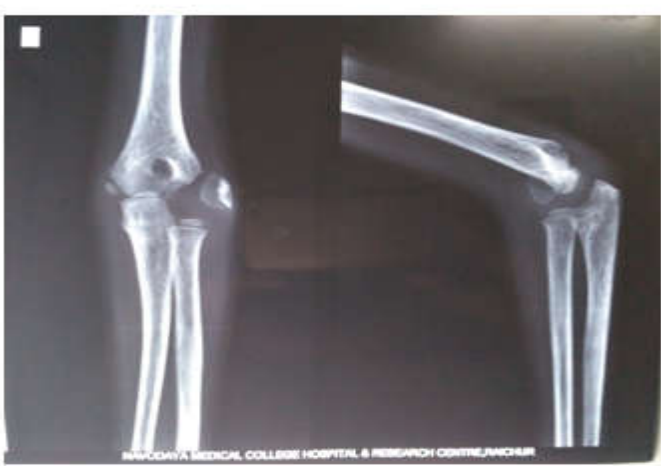

(a) Pre-op x-ray
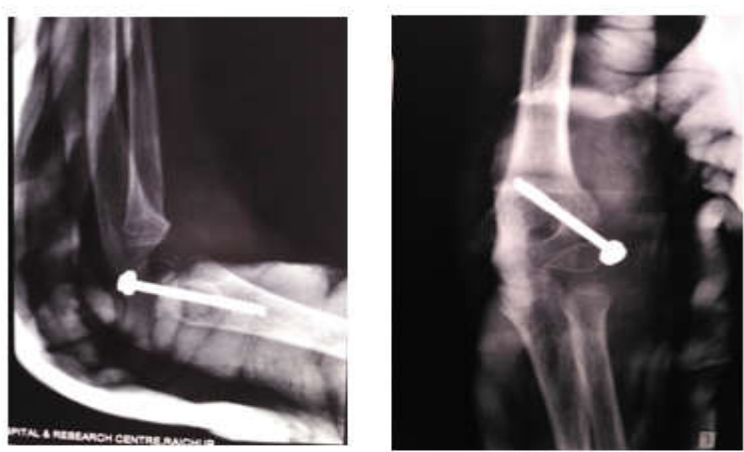

(b) Immediate Post-op x-ray

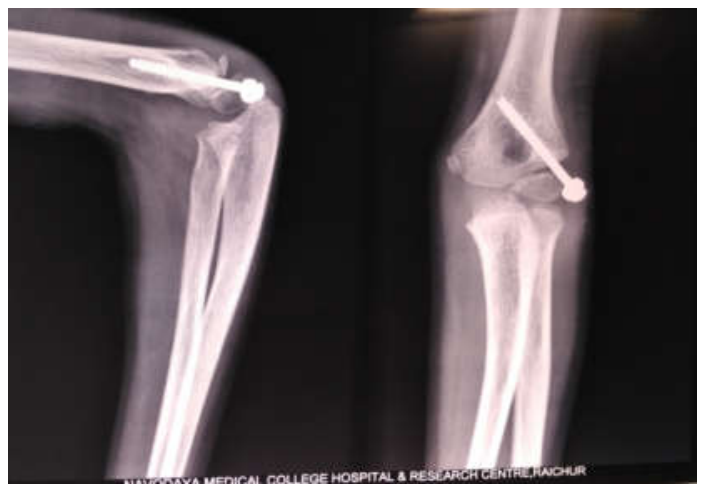

(c) 6 weeks Post-op x-ray

Figure-1: Radiograph course of a 5 year old child with 3 weeks old lateral condyle fracture of the humerus (a, b \& c)
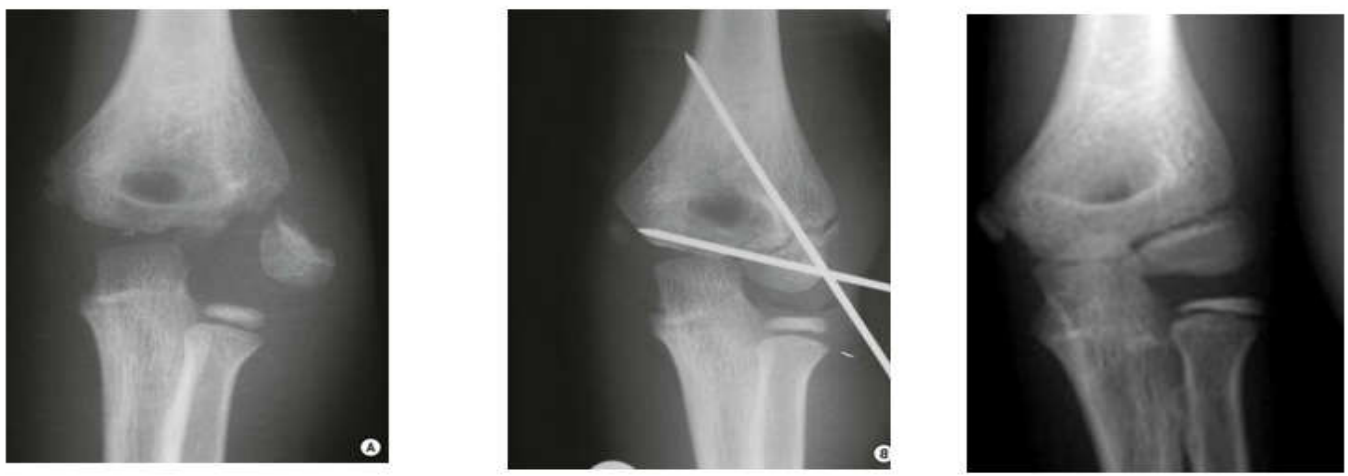

(a) Pre-op x-ray (b) Post-op x-ray (c) x-ray after implant removal at 1 year follow up

Figure- 2: Radiograph course of a 6 year old child with 4 weeks old lateral condyle fracture of the humerus (a, b \& c)

\section{Discussion}

Lateral condyle fracture of the humerus accounts for $17-20 \%$ of elbow fractures in children and most occur between the ages of 2 and 14 years. In developing countries, patients with fractures of the lateral condyle of the humerus usually present late $[8,9]$. There is unanimity of opinion on the need for open reduction and internal fixation of displaced fracture when seen early, but the management of displaced Lateral Condyle Fractures presented at $>3$ weeks after injury is controversial.

In a series of seven cases operated more than 2 weeks after the injury, Jakobs et al reported uniformly bad results. They reported nonunion, malunion, persistent subluxation, limitation of motion and avascular necrosis [7]. Dhillon KS in his study concluded that there is no benefit of operating upon a lateral humeral condyle fracture presenting more than 6 weeks after the injury [4]. Many others have also found delayed open reduction unsatisfactory $[7,9,10]$. 
However, Wattenbarger et al reported that 3 late presented ( $<7$ weeks) children achieved good functional results after open reduction of a displaced fragment and no AVN [5]. Some authors like S K Saraf [11] advocate that satisfactory results can be obtained even at 12 weeks after the initial injury, provided due precautions have been taken during the dissection and with slight modification of surgical procedure in older cases of injury. Sulaiman et al [12] using modified surgical technique for neglected fracture lateral humeral condyle successfully treated patients in his study and did not found any significant avascular necrosis. Shimada et al [13] had successfully treated the nonunion lateral condyle of humerus presenting at an average period of five years after the injury. Agarwal et al [14] retrospectively studied the outcome of attempt of osteosynthesis in 22 children presenting late with lateral condyle fracture of humerus. Their study showed high rate of union and satisfactory elbow function in late presenting cases.

With recent reports supporting surgical intervention in late presenting fractures of lateral condyle humerus, we undertook the study and performed open reduction and internal fixation using k wires and cancellous screws and found $38.46 \%$ excellent, $38.46 \%$ good, $15.38 \%$ fair, and 7.6\% poor results according to the scoring system proposed by Dhillon et al.[4] was used. In a study done by ki cheor bae et al. [15] got 75\% excellent and 25\% good and no patients got fair or poor results. In another study done by Nguyen Ngoc Hung [16], 38.1\% Excellent; 33.3\% got Good; 14.3\% got Fair; and 14.3\% got Poor results which is very much similar to that of results in our study as depicted in (Table 3). In a study by ki cheor bae et al [16] AVN of lateral condyle was not noticed and one case of AVN of lteral condyle of humerus was noted by Nguyen Ngoc Hung [16] which is same as obtained in our study and we had similar minor complications (Table 4) as compared to studies done by the same authors.

Table- 3: Showing comparisons of results using scoring system by Dhillon et al.

\begin{tabular}{|c|c|c|c|c|c|}
\hline \multicolumn{2}{|c|}{ Sl. No } & Study & \multicolumn{3}{|c|}{ Results obtained using scoring system proposed by Dhillon et al } \\
\hline \multicolumn{2}{|c|}{} & Excellent & Good & Fair & Poor \\
\hline 1 & Our Study & $38.46 \%$ & $38.46 \%$ & $15.38 \%$ & $7.6 \%$ \\
\hline 2 & Ki cheor bae et al [15] & $75 \%$ & $25 \%$ & Nil & nil \\
\hline 3 & Nguyen Ngoc Hung [16] & $38.1 \%$ & $33.3 \%$ & $14.3 \%$ & $14.3 \%$ \\
\hline
\end{tabular}

Table- 4: Complications noted after surgery.

\begin{tabular}{|c|c|c|}
\hline Complication & Type & No \\
\hline Major & AVN of lateral condyle & 1 \\
\hline \multirow{2}{*}{ Minor } & Pin tract infections k-wire & 3 \\
\cline { 2 - 3 } & Residual flexion deformity of elbow & 1 \\
\cline { 2 - 3 } & elbow stiffness & 1 \\
\hline
\end{tabular}

Limitations- There are some limitations of the study that should be considered. The primary limitation of our study was that it was a small prospective study including a small number of patients and done at a single center. Larger randomized controlled trials are needed to further evaluate outcomes and complications. We interpreted our results in comparison with those of the studies in the literature that used other methods. However, the outcomes achieved with the technique in this study were favourable.

\section{Conclusion}

Though topic is in much debate and various studies yeilding confusing results, We conclude from our study that late presenting fracture of lateral condyle of humerus needs surgical intervention which can be reasonably reduced and union achieved obtaining satisfactory functional outcome. As the lateral condyle also contributes in lower humeral growth, achieving union helps to shape the condyle geometry, thereby preventing the long term complications of nonunion viz. cubitus valgus deformity, lateral instability of elbow, tardy ulnar nerve palsy.
Both the author's were involved completely and equally contributed from patient selection, surgery, follow up and data collection, manuscript preparation.

Acknowledgements- We thank Dr. Rajani R for her valuable contribution in helping to collect the data and helping to design tables during manuscript preperation.

Conflict of interest: None declared.

Funding: Nil, Permission from IRB: Yes

Ethical approval: Taken 


\section{References}

1. Landin LA, Danielsson LG. Elbow fractures in children. An epidemiological analysis of 589 cases. Acta Orthop Scand. 1986 Aug;57(4):309-12.

2. Foster DE, Sullivan JA, Gross RH. Lateral humeral condylar fractures in children. J Pediatr Orthop. 1985 JanFeb; 5 (1):16-22.

3. De Boeck H. Surgery for nonunion of the lateral humeral condyle in children. 6 cases followed for 1-9 years. Acta Orthop Scand.1995; 66: 401-402, DOI:10. $3109 / 17453679508995573$.

4. Dhillon KS, Sengupta S, Singh BJ. Delayed management of fracture of the lateral humeral condyle in children. Acta Orthop Scand. 1988 Aug; 59 (4): 419-24.

5. Wattenbarger JM, Gerardi J, Johnston CE. Late open reduction internal fixation of lateral condyle fractures. $\mathrm{J}$ Pediatr Orthop. 2002 May-Jun;22(3):394-8.

6. Fontanetta, P., Mackenzie, D.A. and Rosman, M. Missed, Maluniting, and Malunited Fractures of the Lateral Humeral Condyle in Children. Journal of TraumaInjury Infection \& Critical Care.1978; 18, 329-335. DOI: 10. 1097/00005373-197805000-00006.

7. Jakob R, Fowles JV, Rang M, Kassab MT. Observations concerning fractures of the lateral humeral condyle in children. J Bone Joint Surg Br. 1975 Nov;57 (4): 430-6.

8. Song $\mathrm{KS}$, Kang $\mathrm{CH}$, Min $\mathrm{BW}$, Bae $\mathrm{KC}$, Cho $\mathrm{CH}$. Internal oblique radiographs for diagnosis of nondisplaced or minimally displaced lateral condylar fractures of the humerus in children. J Bone Joint Surg Am. 2007 Jan; 89 (1) : 58-63.
9. Hardacre JA, Nahigian SH, Froimson AI, Brown JE. Fractures of the lateral condyle of the humerus in children. J Bone Joint Surg Am. 1971 Sep;53(6):1083-95.

10. Smith FM. An eighty-four year follow-up on a patient with ununited fracture of the lateral condyle of the humerus. A case report. J Bone Joint Surg Am. 1973 Mar; $55(2): 378-80$.

11. Saraf SK, Khare GN. Late presentation of fractures of the lateral condyle of the humerus in children. Indian $\mathrm{J}$ Orthop. 2011 Jan;45(1):39-44. doi: 10.4103/0019-5413. 67119.

12. Sulaiman AR, Munajat I, Mohd EF. A modified surgical technique for neglected fracture of lateral humeral condyle in children. J Pediatr Orthop B. 2011 Nov;20(6):366-71. doi: 10.1097/BPB.0b013e32834920df.

13. Shimada K, Masada K, Tada K, Yamamoto $T$. Osteosynthesis for the treatment of non-union of the lateral humeral condyle in children. J Bone Joint Surg Am. 1997 Feb;79(2):234-40.

14. Agarwal A, Qureshi NA, Gupta N, Verma I, Pandey DK. Management of neglected lateral condyle fractures of humerus in children: A retrospective study. Indian J Orthop. 2012; 46(6): 698-704.

15. Ki Cheor Bae et al., Surgical Treatment of Late Presented Displaced Lateral Condylar Fracture of the Humerus in Children. J Korean Orthop Assoc 2008; 43: 24-29.

16. Hung, N.Kirschner Wire Fixation of Neglected Lateral Condylar Fracture of the Humerus in Children. Open Access Library Journal.2017; 4:1-19.DOI: 10.4236/ oalib. 1103330 .

\section{How to cite this article?}

Reddy P.K.P, Veerabhadra J. Late presenting lateral condyle fracture of the humerus in children - clinical outcome of surgical fixation. 2017;3(3):87-92.doi:10.17511/ijoso.2017.i03.07. 